\title{
Investigation of Mechanical Properties of Banana-Glass Fiber Reinforced Hybrid Composites
}

\author{
Kazi Jubair, Md. Shariful Islam* and Dipto Chakraborty
}

Department of Mechanical Engineering, Khulna University of Engineering and Technology, Khulna-9203, Bangladesh.

Received: February 24, 2021, Revised: October 23, 2021, Accepted: October 31, 2021, Available Online: November 09, 2021

\begin{abstract}
Banana stems are very cheap and abundant in nature which can be used to extract fiber. In this paper, banana fiber is used as a reinforcement and epoxy as a matrix to manufacture banana fiber-reinforced epoxy composite. Glass fiber mat, and roving are also used as reinforcement along with banana fiber to manufacture hybrid composites. The objective of this paper is to compare the mechanical properties of hybrid composites with that of pure banana fiber-reinforced composites. The hand lay-up method is used to manufacture all the composites, and tensile and flexural properties are investigated according to the corresponding ASTM standard. It is found that the tensile and flexural strength of banana and glass fiber roving hybrid composites are much higher compared to pure banana fiber-reinforced epoxy composites which make this hybrid composite suitable for low strength application.
\end{abstract}

Keywords: Banana Fiber; Hybrid Composite; Tensile Strength; Flexural Strength.

This work is licensed under a Creative Commons Attribution-Non Commercial 4.0 International License.

\section{Introduction}

The typical composite material consists of reinforcement and matrix phase where the constituent materials are distinguishable by observing their appearance. It is very popular in the aerospace and automobile industries because of its higher strength to weight ratio [1]. Based on the type of reinforcement, it is classified as natural fiber and synthetic fiber composite. Natural fiber composite includes jute, flax, bamboo, banana, kenaf fiber, etc., which are directly extracted from natural sources. Synthetic fiber includes glass, carbon, Kevlar fiber, etc. If more than one type of fiber is used for reinforcement, then the composite is known as a hybrid composite. In this paper, both natural and synthetic fiber-reinforced composite is studied along with their hybrid composite.

Hybrid composites with more than one reinforcing material shows preferable mechanical properties because the mechanical properties can be tailored according to specific needs. Natural fiber and its hybrid composites could be used as a replacement of wood in shelves, partitions, tabletop, and it can also be used as interior parts in automobile industries, and as construction materials such as walls and roofs, packaging industries, fishing boats etc. [2], [3] and [4]. Munoz et al. studied mechanical properties of flax fiber-reinforced bio-epoxy composites for various fiber volume fractions and found that swelled flax fiber composites showed preferable mechanical properties over the dried one [5]. Islam et al. studied the mechanical properties of banana and rattan fiber reinforced epoxy composite and reported that the tensile strength of the banana fiber is higher compared to rattan fiber [6]. Maleque et al. investigated the mechanical properties of woven banana fiber reinforced composites with epoxy as a matrix [7]. Pothan et al. found the optimum fiber volume fraction is $40 \%$ while investigating the mechanical properties of banana fiber reinforced polyester composite [8]. An investigation on banana fiber reinforced green composite carried out by Sharma et al. reveals that the mechanical properties are better at $15 \mathrm{wt} \%$ fiber reinforcement [9]. The effect of fiber length and volume fraction is studied by Venkateshwaran et al. where they have found $15 \mathrm{~mm}$ fiber length and $16 \%$ fiber volume fraction give optimum properties [10]. Joseph et al. studied the mechanical properties of banana and glass fiber reinforced hybrid composite and reported that hybrid composite with better mechanical properties can be manufactured using banana and glass fiber as reinforcements which leads to this investigation [11].

In this paper, the mechanical properties of banana, glass fiber roving, glass fiber mat, and hybrid banana/glass fiber (both mat and roving) are extensively studied. Since the strength of the glass fiber mat and roving is higher compared to banana fiber, it is expected that the hybrid composite would give better strength compared to pure banana fiber-reinforced composite. This paper compares the mechanical properties of banana/glass fiber mat and banana/glass fiber roving composites with that of pure banana fiber-reinforced composites. The following sections describe the composite manufacturing process, mechanical testing, results and discussions followed by the conclusion.

\section{Materials and Methods}

\subsection{Materials}

Banana, E-glass fiber mat, and roving are used as reinforcements, and LY 556 epoxy with HY 951 hardener is used for matrix material in this investigation. Banana stem is purchased from the local market, and this banana stem is used to extract the fiber, as discussed in the following section.

\subsection{Fiber Extraction}

The stem is the part of the banana plant that looks like a trunk that is used for fiber extraction. This part of the plant was squeezed out about $60 \%$ of the water and lignin. After that, it was left 10 to 15 days within rotten water. After 15 days, the lignin of the banana stem is completely dissolved in the water and then the fiber is washed with clean water. The extracted fiber is then dried in the open air at room temperature. Fig. 1 shows the different steps involved in the fiber extraction process. 


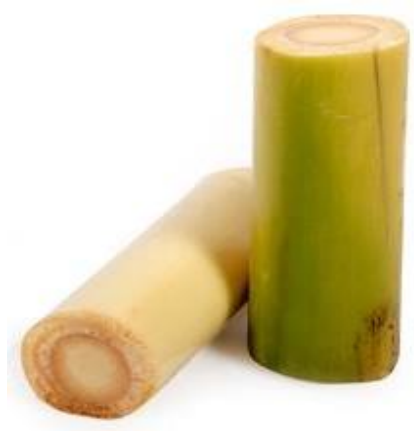

(a)

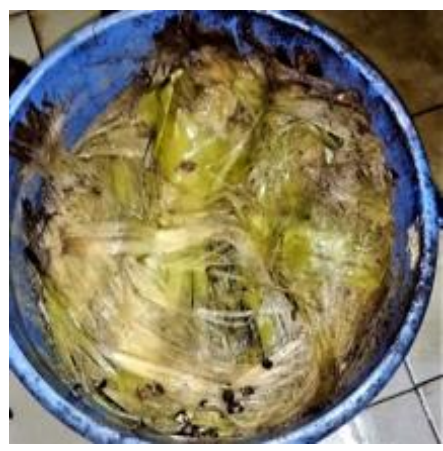

(d)

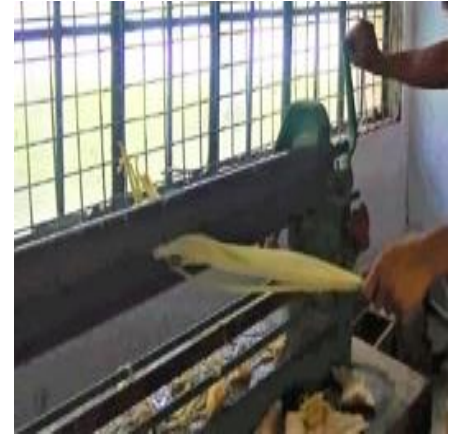

(b)

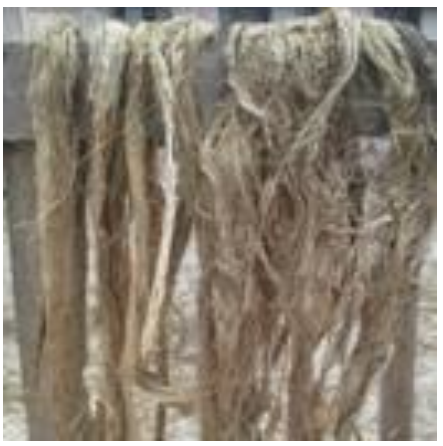

(e)

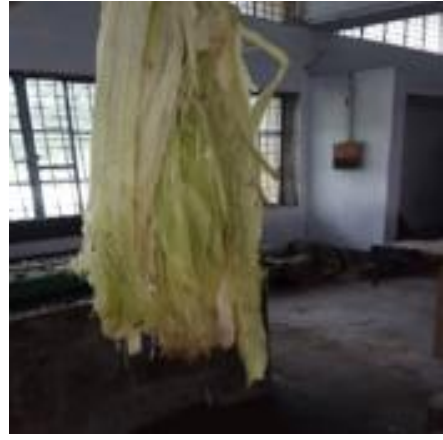

(c)

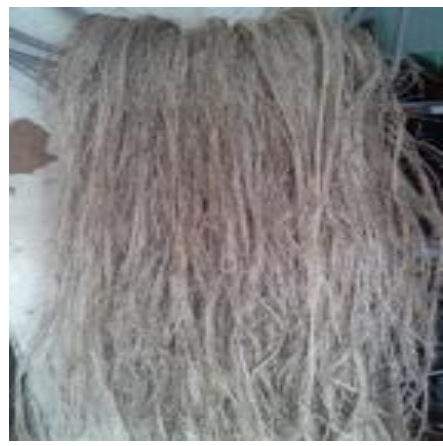

(f)

Fig. 1 Extraction of banana fiber (a) banana stem, (b) manual rolling of the stem, (c) rolled stem, (d) stem in rotten water, (e) drying of extracted fiber, and (f) extracted fiber.

\subsection{Composite Fabrication}

The hand lay-up technique is used to manufacture the composites, which is a popular and effective way [12], [13]. Fig. 2 shows [14] the typical hand lay-up molding process. The mold release agent is applied over the top and bottom mold plate at the beginning, and then epoxy and hardener mixture is applied on the bottom mold plate with the help of a brush. A roller is then used to evenly distribute the epoxy. The first layer of the reinforcing materials is then placed on top of that and again epoxy is poured and rolled over the layer. This process is repeated until the final layer of the reinforcing material. Once all the reinforcing layer is stacked, then the top mold plate is placed and a pressure of $100 \mathrm{MPa}$ is applied on top of the mold plate. The set-up is kept like this way for 24 hours at room temperature to allow the matrix to cure. After 24 hours, the manufactured composite is demolded and cut into small pieces according to the corresponding ASTM standard for mechanical testing. Fig. 3 shows the manufactured composite.

Hand Lay-Up

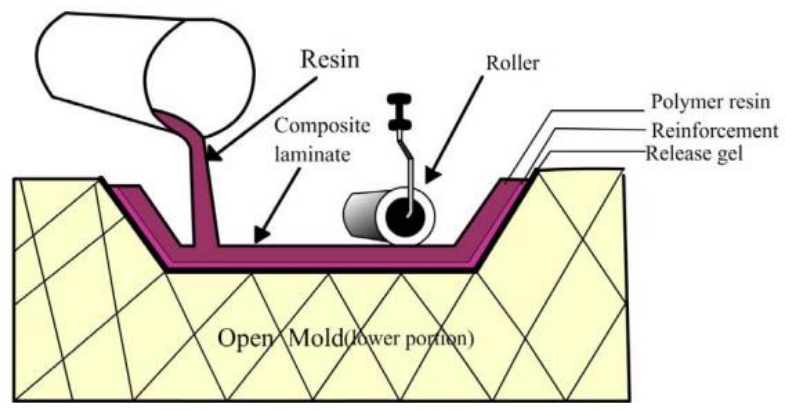

Fig. 2 Schematic diagram of hand lay-up process [14].

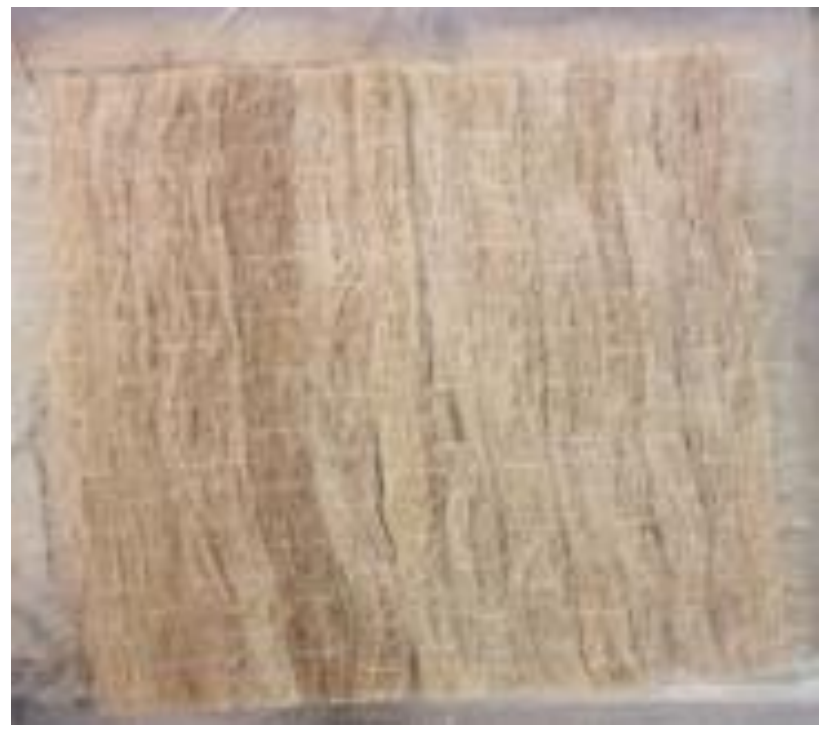

Fig. 3 Manufactured composite.

\subsection{Tensile Test}

Tensile tests on four types (banana, glass, hybrid 1, and hybrid 2) manufactured composites are performed according to ASTM D3039 standard [15]. Hybrid 1 consists of two layers of banana fiber and two layers of glass fiber mat while hybrid 2 consists of two layers of banana fiber along with two layers of glass fiber roving. For hybrid composites, the glass fiber (mat/roving) layers are used as the top and bottom layers since these layers experience maximum stress compared to the inner two layers. Specimens are cut along parallel to the fiber direction, and 5 specimens are tested for each type of composite. Fig. 4 shows the tensile test specimen with dimension, the average thickness of the specimens is $6 \mathrm{~mm}$. Tensile specimens are 
loaded on a SHIMADZU (AGX-300KNV) universal testing machine while the loading rate is $2 \mathrm{~mm} / \mathrm{min}$ and tested until the specimens fail. Equation 1 is used to calculate the ultimate tensile strength according to the ASTM D3039 standard [15].

$$
F^{t u}=P^{\max } / A
$$

Where, $F^{t u}$ is ultimate tensile strength, $\mathrm{MPa}$

$P^{\max }$ is the maximum force before failure, $\mathrm{N}$

$\mathrm{A}$ is the cross-sectional area, $\mathrm{mm}^{2}$.

Tensile chord modulus of elasticity is calculated according to equation 2, and for this calculation, the absolute tensile strain of 0.001 to 0.003 is used as suggested by ASTM D3039 standard [15].

$$
E^{\text {chord }}=\Delta \sigma / \Delta \varepsilon
$$

Where, $E^{\text {chord }}$ is the tensile chord modulus of elasticity, $\mathrm{GPa}$,

$\Delta \sigma$ is the difference in applied tensile stress between the two strain points ( 0.001 and 0.003$), \mathrm{MPa} \Delta \varepsilon$ is the difference between two strains (0.002).

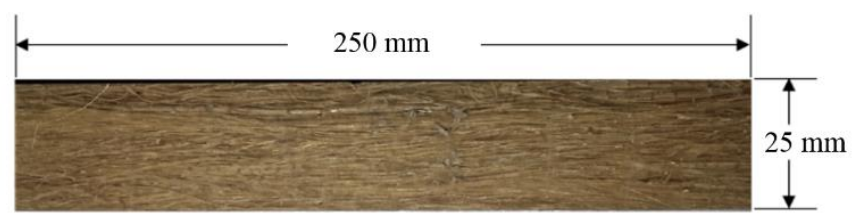

Fig. 4 Tensile test specimen with dimension.

\subsection{Flexural Test}

The flexural properties of the manufactured composites are determined by performing three-point bending tests. The test specimens are cut and tested according to ASTM D 7264 [16] with a span-to-thickness ratio of 32:1. Five specimens of each type are tested in the same SHIMADZU (AGX-300KNV) universal testing machine, and the loading rate of $1.0 \mathrm{~mm} / \mathrm{min}$ is maintained. All the specimens are tested until failure. Fig. 5 shows the three-point bending test specimen with dimension.

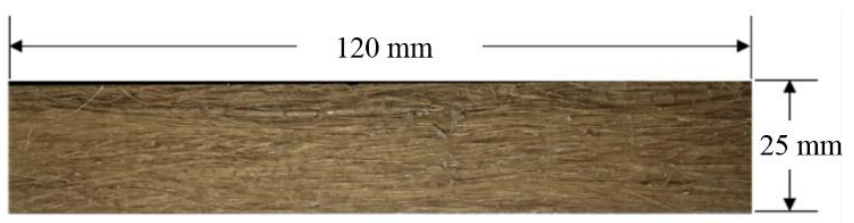

Fig. 5 Three-point bend test specimen with dimension.

The flexural strength of the specimens is calculated using the following equation from ASTM D 7264 [16].

$$
\sigma=\frac{3 P L}{2 b h^{2}}
$$

Where, $\sigma$ is the flexural strength, $\mathrm{MPa}$

$\mathrm{P}$ is the maximum applied force, $\mathrm{N}$

$\mathrm{L}$ is the support span, $\mathrm{mm}$

$\mathrm{b}$ is the specimen width, $\mathrm{mm}$

$\mathrm{h}$ is the thickness of the specimen, $\mathrm{mm}$.

Flexural chord modulus of elasticity is calculated by following ASTM D 7264 [16] standard with a similar equation of (2).

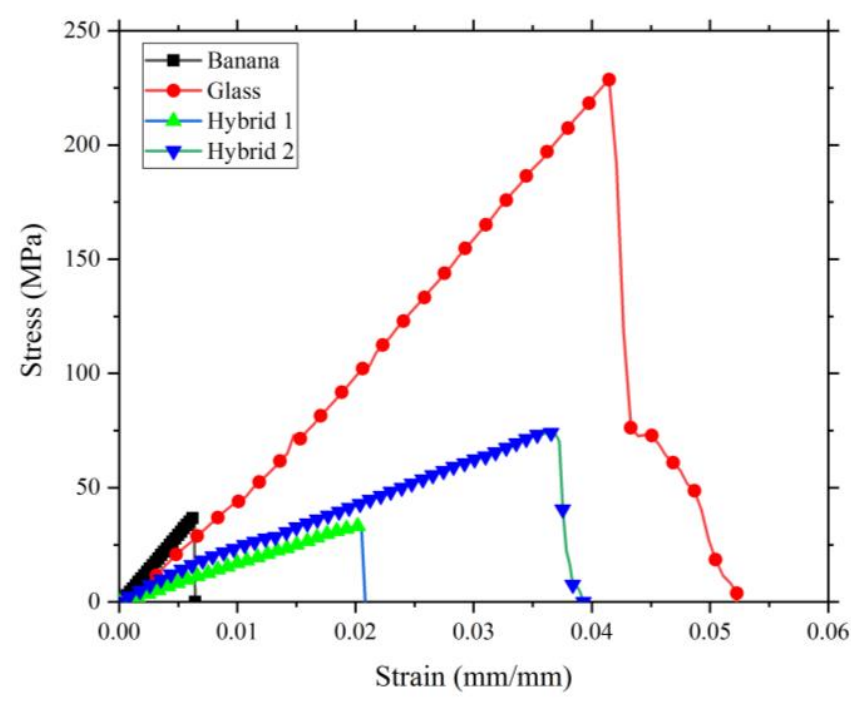

Fig. 6 Stress-strain diagram for the tensile test.

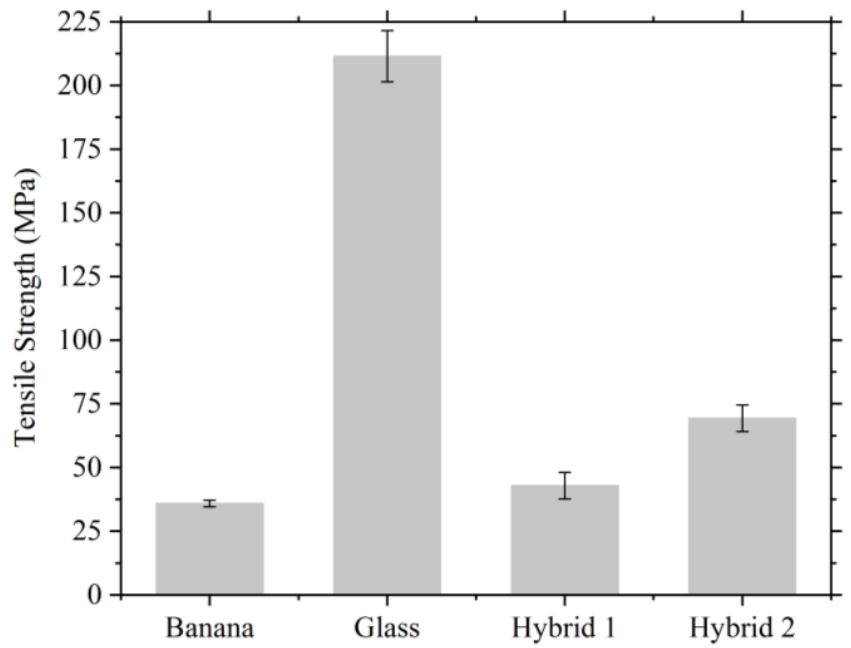

(a)

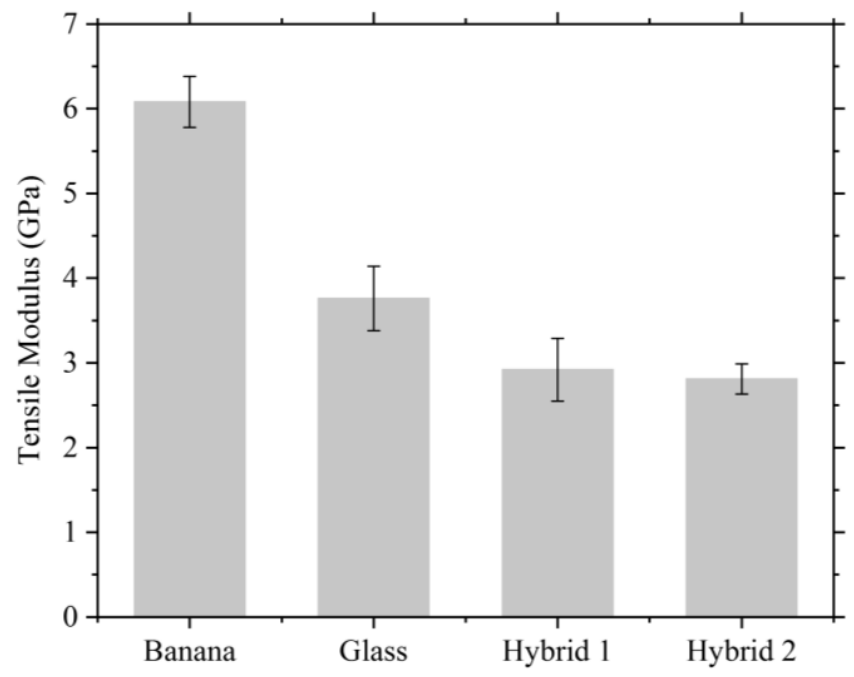

(b)

Fig. 7 Tensile test results (a) Strength and (b) Modulus. 


\section{Results \& Discussion}

\subsection{Tensile test}

The typical stress-strain diagram for all four types of composites is shown in Fig. 6. It is observed from this figure, that the maximum stress is minimum for banana fiber composite and maximum for glass fiber composite. The maximum stresses of hybrid 1 and hybrid 2 are between the banana and glass fiber composite which can be also found in Fig. 7 (a). The slope of the stress-strain diagram for banana fiber composite is maximum which indicates that the tensile modulus (refer to Fig. 7 (b)) is maximum for banana fiber composite.

The tensile strength of different composites is shown in Fig. 7 (a) and the tensile modulus is shown in Fig. 7 (b). From Fig. 7 (a), it is found that the tensile strength of the banana fiber is minimum and that of glass fiber is maximum, while for hybrid composite, the tensile strength is in between banana and glass fiber composites. The average tensile strength of banana fiber composite is $35.86 \mathrm{MPa}$, for hybrid 1 is $42.83 \mathrm{MPa}$ and for hybrid 2 is $69.28 \mathrm{MPa}$. This indicates $19.44 \%$ and $93.20 \%$ increase in tensile strength for hybrid 1 and hybrid 2 respectively compared to banana fiber composite.

The tensile modulus of the Banana fiber composite is higher compared to the other three composites as shown in Fig. 7 (b). For hybrid 1 and 2, $51.97 \%$ and $53.78 \%$ lower flexural modulus is found compared to Banana fiber composites. One reason could be the lay-up because two glass fiber layers were placed in between two Banana fiber layers

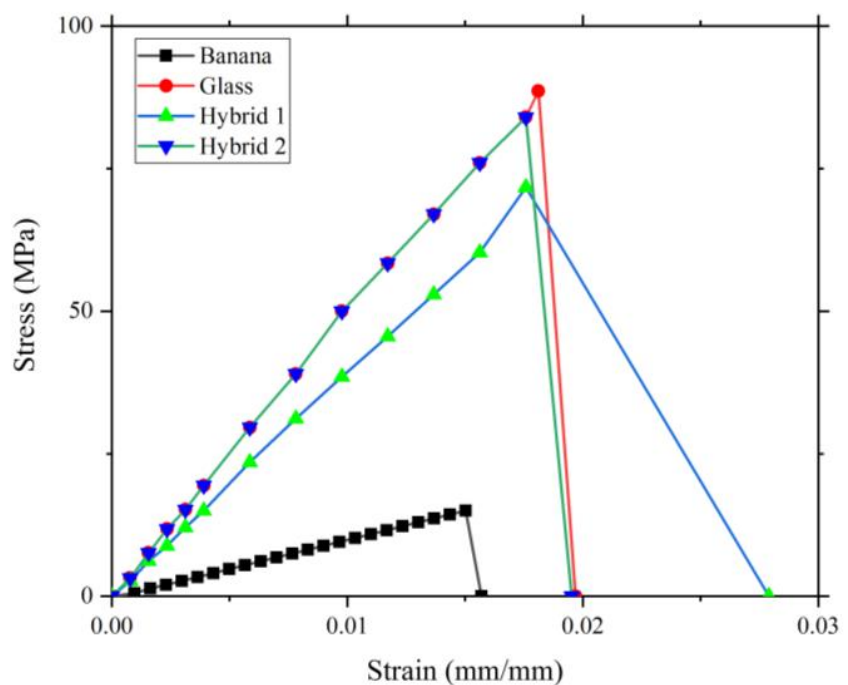

Fig. 8 Stress-strain diagram for the flexural test.

\subsection{Flexural Test}

The typical stress-strain diagram for all four types of composites is shown in Fig. 8. It is observed from this figure that the maximum stress for banana fiber is minimum compared to other composites which indicates that flexural strength for banana fiber composite is lower than the other composites. Flexural modulus is calculated for these composites using this stress-strain diagram and shown in Fig. 9 (b).

Fig. 9 shows flexural strength and flexural modulus of different composites. It is perceived from Fig. 9 that the flexural strength of Banana fiber composite is minimum and for Glass fiber is maximum. For hybrid 1 and 2, the flexural strength is found between the Banana and Glass fiber composites. The average flexural strength of Banana fiber composite is 15.68
$\mathrm{MPa}$, for hybrid 1 is $55.95 \mathrm{MPa}$ and for hybrid 2 is found to be $79.99 \mathrm{MPa}$ which suggests a $256.82 \%$ and $410.14 \%$ increase in flexural strength of hybrid 1 and 2 respectively compared to Banana fiber-reinforced composite. The flexural modulus also follows a similar trend of flexural strength.

From the above discussion, it can be said that adding two layers of Glass fiber roving along with two Banana fiber layers can significantly increase the tensile and flexural strength of the composite compared to pure Banana fiber-reinforced composite.

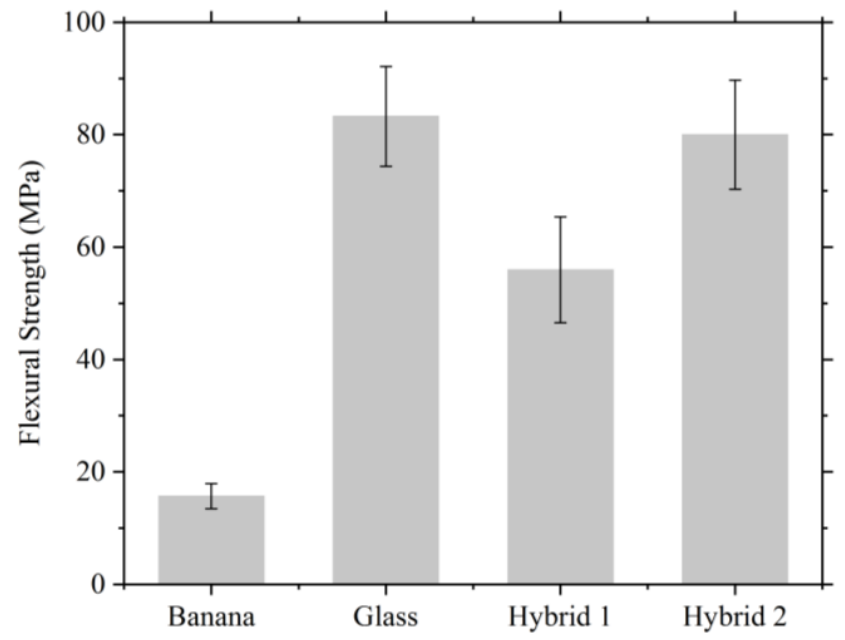

(a)

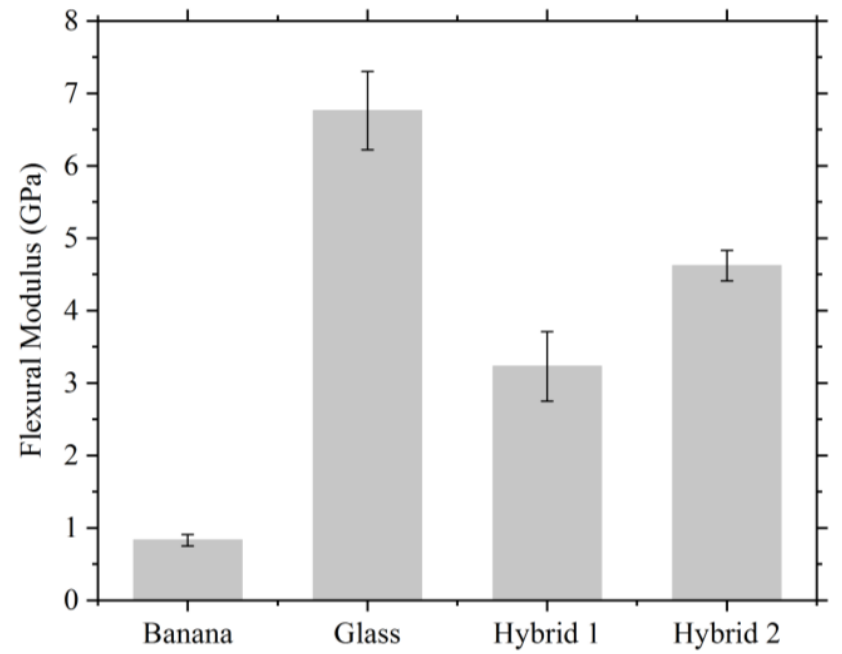

(b)

Fig. 9 Flexural test results (a) Strength and (b) Modulus.

\section{Conclusion}

In this paper, the mechanical properties of four different types of composites are investigated. It is found that adding glass fiber layers along with Banana fiber can significantly increase the tensile and flexural strength compared to banana fiber reinforced composite. Adding glass fiber mat layers in banana fiber composite increased the tensile and flexural strength by $19.44 \%$ and $256.82 \%$ respectively while adding glass fiber roving increased these strengths by $93.20 \%$ and $410.14 \%$. So, significant improvement in the tensile and flexural strength is found by adding glass fiber roving with banana fiber. This investigation suggests that the hybrid composites can be used in the automobile door panel, household roofing panel etc. 


\section{References}

[1] Islam, M.S., Avila, R., Castellanos, A.G. and Prabhakar, P., 2016. Hybrid textile composites as potential cryogenic tank materials. In 57th AIAA/ASCE/AHS/ASC Structures, Structural Dynamics, and Materials Conference (p. 1237).

[2] Elbadry, E.A., Aly-Hassan, M.S. and Hamada, H., 2012. Mechanical properties of natural jute fabric/jute mat fiber reinforced polymer matrix hybrid composites. Advances in Mechanical Engineering, 4, pp.354547.

[3] Gupta, M.K. and Srivastava, R.K., 2016. Mechanical, thermal and water absorption properties of hybrid sisal/jute fiber reinforced polymer composite. Indian Journal of Engineering \& Materials Sciences, 23, pp. 231238.

[4] Rafiquzzaman, M., Islam, M., Rahman, H., Talukdar, S. and Hasan, N., 2016. Mechanical property evaluation of glass-jute fiber reinforced polymer composites. Polymers for Advanced Technologies, 27(10), pp.1308-1316.

[5] Muñoz, E. and García-Manrique, J.A., 2015. Water absorption behaviour and its effect on the mechanical properties of flax fibre reinforced bioepoxy composites. International journal of polymer science, 2015.

[6] Islam, M.S., Azmy, S. and Almamun, A., 2019. Comparative study on mechanical properties of banana and rattan fiber reinforced epoxy composites. American Journal of Engineering Research (AJER), 8(2), pp.1-6.

[7] Maleque, M.A., Belal, F.Y. and Sapuan, S.M., 2007. Mechanical properties study of pseudo-stem banana fiber reinforced epoxy composite. The Arabian journal for science and engineering, 32(2B), pp.359-364.

[8] Pothan, L.A., Oommen, Z. and Thomas, S., 2003. Dynamic mechanical analysis of banana fiber reinforced polyester composites. Composites Science and technology, 63(2), pp.283-293.

[9] Sharma, N.K. and Kumar, V., 2013. Studies on properties of banana fiber reinforced green composite. Journal of Reinforced Plastics and Composites, 32(8), pp.525-532.

[10] Venkateshwaran, N., ElayaPerumal, A. and Jagatheeshwaran, M.S., 2011. Effect of fiber length and fiber content on mechanical properties of banana fiber/epoxy composite. Journal of Reinforced Plastics and Composites, 30(19), pp.1621-1627.

[11] Joseph, S., Sreekala, M.S., Oommen, Z., Koshy, P. and Thomas, S., 2002. A comparison of the mechanical properties of phenol formaldehyde composites reinforced with banana fibres and glass fibres. Composites Science and Technology, 62(14), pp.1857-1868.

[12] Asif, M., Rahman, K.A., Faisal, M.O. and Islam, M.S., 2020. Comparative Study on Mechanical Properties of Bamboo and Bamboo-glass Fiber Reinforced Hybrid Composites. Journal of Engineering Advancements, 1(01), pp.06-10.

[13] Chakrabarti, D., Islam, M.S., Jubair, K. and Sarker, M.R.H., 2020. Effect of Chemical Treatment on the Mechanical Properties of Luffa Fiber Reinforced Epoxy Composite. Journal of Engineering Advancements, 1(02), pp.37-42.

[14] https://www.eppcomposites.com/hand-layupprocess.html last accessed October 22, 2021.

[15] Standard, A.S.T.M., 2008. Standard test method for tensile properties of polymer matrix composite materials. ASTM D3039/D M, 3039, p.2008.

[16] ASTM D7264, 2007. Standard test method for flexural properties of polymer matrix composite materials. American Society for Testing and Materials Annual Book of ASTM Standards. 